\title{
Functional status and its associated factors in Nigerian adolescents with bipolar disorder
}

\author{
MO Bakare ${ }^{1}$, AO Agomoh², J Eaton³, PO Ebigbo4, JU Onwukwe \\ ${ }^{1}$ Child and Adolescent Unit, Federal Neuro-Psychiatric Hospital, New Haven, Enugu, Enugu State, Nigeria \\ ${ }^{2}$ General/Forensic Unit, Federal Neuro-Psychiatric Hospital, New Haven, Enugu, Enugu State, Nigeria \\ 3west Africa CBM National Co-ordination Office, P.O.Box 8451, Wuse, Abuja, Nigeria \\ 4Department of Psychological Medicine, University of Nigeria Teaching Hospital, (UNTH), Enugu, Enugu State, Nigeria \\ ${ }^{5}$ Community Psychiatry Unit, Federal Neuro-Psychiatric Hospital, New Haven, Enugu, Enugu State, Nigeria
}

\begin{abstract}
Objective: This study assessed general functioning in Nigerian adolescents with bipolar disorder. It also determined the factors associated with functioning in these adolescents. Methods: Adolescents with bipolar disorder diagnosed over one year or more attending the outpatient unit of Federal Neuro-Psychiatric Hospital, Enugu (FNHE), Nigeria for follow-up visits were interviewed with a socio-demographic questionnaire and their functioning was rated with the Children Global Assessment Scale (C-GAS) based on the clinical information obtained from the children and their care givers during a one year follow-up period. Further information such as history of sexual risk behavior, pre-morbid peer relationship, relationship with siblings, level of religion activities among others were also obtained through clinical interview. Results: A total of 46 adolescents with bipolar disorder were followed up. Minimal to moderate impairment in functioning in the past year was found in these adolescents. The mean score on C-GAS was 68.41 \pm 16.63. Factors including co-morbidity, pre-morbid peer relationship, relationship with siblings, level of religion activities and history of sexual risk behavior were significantly associated with functioning $(p=0.000)$, while marital status of the parents showed a weak association with functioning in these adolescents ( $p=0.068$ ). Negative correlation was also found between mean number of hospital admissions in the past year during follow up and mean score on C-GAS $(r=-0.908, p=0.000)$. Conclusion: Functional impairments complicate bipolar disorder in Nigerian adolescents. To ensure good overall outcome in these adolescents, attention needs to be focused on promoting those factors that help good functioning. Future longitudinal follow up studies that would assess long-term outcome and its correlates in children and adolescents with bipolar disorder in this environment are desirable.
\end{abstract}

Key Words: Functioning; Children; Adolescent; Bipolar Disorder; Nigeria

Received: 19-11-2010

Accepted: 24-01-201 1

doi: http://dx.doi.org/10.4314/ajpsy.vl4i5.7

\section{Introduction}

Bipolar disorder constitutes about twenty percent of mood disorders and is responsible for substantial morbidity and mortality among children and adolescents. ${ }^{1}$ Bipolar disorder course is known to be associated with disability and impaired functioning ${ }^{2}$ and bipolar disorder often shows a continuum of symptom severity with frequent mood fluctuation. ${ }^{3}$ The severity of symptoms and fluctuations of mood in patients with bipolar disorders are known to impact significantly on functioning. ${ }^{4}$ Early onset bipolar disorder, especially in the

\section{Correspondence}

Dr MO Bakare

Child and Adolescent Unit, Federal Neuro-Psychiatric Hospital, New

Haven, Enugu, Enugu State, Nigeria

email: mobakare2000@yahoo.com adolescent period is associated with more co-morbidity, impairment in functioning and poor quality of life. ${ }^{5}$ Despite the high prevalence and enormity of mood disorders among Nigerian children and adolescents, 6,8 , information is lacking on functioning and factors influencing functioning in children and adolescents with bipolar disorder in this environment.

This study therefore assessed functioning in the past one year among adolescents with a diagnosis of either bipolar I or bipolar II disorder based on Diagnostic and Statistical Manual of Mental Disorders, fourth edition (DSM-IV) criteria. ${ }^{9}$ The adolescents were attending follow up visits to the outpatient unit of the Federal Neuro-Psychiatric Hospital, New Haven, Enugu, (FNHE), Nigeria over the one year period between January to December, 2008. We also determined those factors influencing functioning in these adolescents with bipolar disorder. 


\section{Method}

\section{Participants}

Adolescents attending the outpatient unit of FNHE, Nigeria on follow up visits with a diagnosis of either bipolar I or bipolar II disorder based on DSM-IV criteria and who had the first episode of their illness at least one year preceding the period of outpatient follow-up (January to December, 2008) were included and interviewed for the study. The included adolescents were eighteen years of age and below at the time of follow-up.

\section{Ethical consideration}

The nature of the study was explained to the participants and consent was obtained from the adolescents and their caregivers. The permission to carry out the study was obtained from the Institutional Review Board (IRB) of FNHE, Nigeria.

\section{Materials}

- Socio-demographic questionnaire:

Socio-demographic questionnaire was designed to obtain information including gender, age, age at onset of illness, number of hospital admissions in the past year during the period of follow up, marital status of the parents.

- Children's Global Assessment Scale (C-GAS):

Children's Global Assessment Scale (C-GAS) is a numeric scale (1 to 100) designed to be used by clinicians to rate functioning in children less than 18 years of age independent of the specific mental health diagnosis. It was adapted from the adult Global Assessment of Functioning (GAF). ${ }^{10} \mathrm{C}-\mathrm{GAS}$ was designed and described by Schaffer and colleagues in 1983.10 This assessment scale (C-GAS) was used to assess the social, educational and psychological functioning of the adolescents studied over the one year period of follow up. Earlier pilot survey of inter-rater reliability of C-GAS at FNHE, Nigeria gave a correlation of 0.91 (Unpublished data). Average rating of two independent clinicians was documented for each child both at the beginning and end of follow-up period.

\section{Procedure}

The above instruments were used to obtain information from the participating children and adolescents and their care givers. Further clinical interview was employed to obtain history of premorbid peer relationships, relationships with siblings, co-morbid substance use, compliance with medications, sexual risk behavior (defined as having unprotected sexual intercourse, intercourse with commercial sex workers, sexual intercourse with multiple partners without protection), and level of religious activities (which was rated as 'high' if the adolescent participated in worship/church activities for more than twice a week; 'moderate' if once to twice a week; and 'low' if fortnightly or not at all). The clinical interview and assessment at follow up visits provided the basis on which functional status of these adolescents in the past year was rated on the C-GAS. The C-GAS was administered twice (at the beginning and at the end of follow-up period). The mean score of these two measures was recorded for individual children.

\section{Data Analysis}

Data were analyzed using the Statistical Package for Social Sciences, (SPSS) version 15.

The mean score of the adolescents on C-GAS was calculated. Socio-demographic variables and other clinical parameters were related with the adolescents' mean score on C-GAS to determine the factors that were significantly associated with functioning in these adolescents in the past year. Qualitative inter group data were analyzed with Chi-square test, while quantitative inter group data were analyzed by correlation statistics.

\section{Results}

A total of forty six (46) adolescents with bipolar disorder participated in the study. There were 29 (63.0\%) males and 17 (37.0\%) females. The age range of the adolescents was between 15 and 18 years; the mean age was $16.90 \pm 1.07$. The mean age at onset of bipolar disorder symptoms in the adolescents was 15.02 \pm 1.02 . The mean number of hospital admissions in the past year during follow up period among the adolescents was $2.85 \pm 1.07$. Table I shows the socio-demographic variables and clinical parameters of the adolescents with a diagnosis of bipolar disorder.

\begin{tabular}{|c|c|}
\hline Socio-demographic variables & $N(\%)$ \\
\hline $\begin{array}{l}\text { Gender } \\
\text { Male } \\
\text { Female }\end{array}$ & $\begin{array}{l}29(63.0) \\
17(37.0)\end{array}$ \\
\hline $\begin{array}{l}\text { Age (Years) } \\
15 \\
16 \\
17 \\
18\end{array}$ & $\begin{array}{l}6(13.0) \\
11(23.9) \\
12(26.1) \\
17(37.0)\end{array}$ \\
\hline $\begin{array}{l}\text { Marital Status of the Parents } \\
\text { Married } \\
\text { Divorced/Separated/Widowed }\end{array}$ & $\begin{array}{l}28(60.9) \\
18(39.1)\end{array}$ \\
\hline $\begin{array}{l}\text { Co-morbid disorders } \\
\text { Present } \\
\text { Absent }\end{array}$ & $\begin{array}{l}22(47.8) \\
24(52.2)\end{array}$ \\
\hline $\begin{array}{l}\text { Pre-morbid Peer Relationship } \\
\text { Good } \\
\text { Poor }\end{array}$ & $\begin{array}{l}34(73.9) \\
12(26.1)\end{array}$ \\
\hline $\begin{array}{l}\text { Level of Religion Activities } \\
\text { High } \\
\text { Moderate } \\
\text { Low }\end{array}$ & $\begin{array}{l}12(26.1) \\
16(34.8) \\
18(39.1)\end{array}$ \\
\hline $\begin{array}{l}\text { History of Sexual Risk Behavior } \\
\text { Present } \\
\text { Absent }\end{array}$ & $\begin{array}{l}21(45.7) \\
25(54.3)\end{array}$ \\
\hline $\begin{array}{l}\text { Relationship with Siblings } \\
\text { Good } \\
\text { Poor }\end{array}$ & $\begin{array}{l}27(58.7) \\
19(41.3)\end{array}$ \\
\hline $\begin{array}{l}\text { Number of Hospital Admissions in the Past Year } \\
1 \\
2 \\
3 \\
4\end{array}$ & $\begin{array}{l}6(13.0) \\
12(26.1) \\
11(23.9) \\
17(37.0)\end{array}$ \\
\hline $\begin{array}{l}\text { C- GAS Mean Score Groups } \\
\text { Mean Score and Above } \\
\text { Below the Mean Score }\end{array}$ & $\begin{array}{l}23(50) \\
23(50)\end{array}$ \\
\hline
\end{tabular}


Table II: Correlation between functioning (scores on C-GAS) and number of hospital admissions in the past year

\begin{tabular}{|l|l|l|l|l|}
\hline Variables & Means & Standard Deviation & Pearson Correlation (r) & $p$ - value \\
\hline Number of Hospital Admissions (Past Year) & 2.85 & 1.07 & & \\
Vunctioning in the Past Year (C-GAS Score) & 68.41 & & $-0.908^{\star}$ & \\
\hline * Negative correlation which is significant at $\leq 0.05$. & & & \\
\hline
\end{tabular}

\section{Number of hospital admissions and functioning in the past year}

There was a negative correlation between the mean number of hospital admissions in the past year and the mean score on CGAS. Table II shows the correlation between functioning as measured by the adolescents' scores on C-GAS and number of hospital admissions in the past year.

\section{Functional status and the associated factors}

The adolescents' functioning scores on C-GAS ranged between 45 and 92. The mean functioning score on C-GAS for the participating adolescents with bipolar disorder was 68.41 \pm 16.63 , which implied that on average there were some difficulties. Fifty percent of these adolescents had scores below the mean functioning score on C-GAS for the entire population of children studied. The adolescents were divided into two groups (those that scored below the mean score and those that had a value of mean score and above on C-GAS). The two groups were related with the socio-demographic variables and clinical parameters of the adolescents.

Presence of co-morbid disorders $\left(\chi^{2}=41.87, \mathrm{df}=1, \mathrm{p}=\right.$ 0.000), poor pre-morbid peer relationship $\left(\chi^{2}=20.96, \mathrm{df}=1\right.$, $\mathrm{p}=0.000)$, 'low' level of religion activities $\left(\chi^{2}=43.90, \mathrm{df}=2, \mathrm{p}\right.$ $=0.000)$, history of sexual risk behavior in the past year $\left(\chi^{2}=\right.$ 15.77, $\mathrm{df}=1, \mathrm{p}=0.000)$, poor relationship with siblings $\left(\chi^{2}=\right.$ 41.12, df $=1, p=0.000$ ) were all significantly associated with having a score below the mean score on C-GAS. Marital status of the parents of the adolescents was also approaching a significant association with functioning $\left(\chi^{2}=2.36, \mathrm{df}=1, \mathrm{p}=\right.$ 0.068), with adolescents of single parents more likely to have a

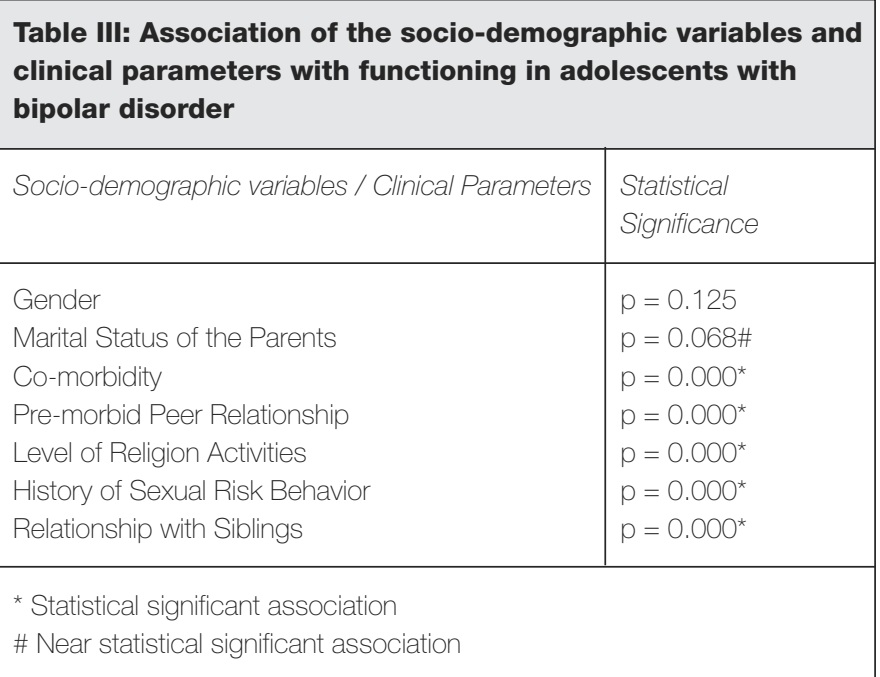

score below mean score on C-GAS. Gender was not significantly associated with functioning as measured by mean score on C-GAS $\left(\chi^{2}=2.36, d f=1, p=0.125\right)$. Table III shows the association of the socio-demographic variables and clinical parameters with functioning in the adolescents.

\section{Discussion}

The mean functioning score for the adolescents with bipolar disorder in the past year falls within the range of 70-61 on CGAS scale, which implies some level of difficulties, though minimal. However, fifty percent of the adolescents had scores below the mean score on C-GAS for the total population, which is an indication that functioning as measured by C-GAS scores varied in the individual adolescents.

The factors that distinguished those adolescents that had scores below the mean score and those with the value of mean score and above included presence of co-morbid disorders, poor pre-morbid peer relationship, 'low' level of religious activities, history of sexual risk behavior and poor relationship with the siblings. Marital status of the parents also minimally influenced functioning in these adolescents with bipolar disorder. The detail of associated co-morbid disorders in these adolescents had been reported elsewhere. ${ }^{11}$

The mean number of hospital admissions of these adolescents in the past year was negatively correlated with the mean functioning score of the adolescents on C-GAS, implying that the higher the number of hospital admissions in the past year, the lower the score on C-GAS. Number of hospital admissions in the past year during the outpatient follow up is a function of frequency of symptoms relapse or recurrence in adolescents with bipolar disorder and frequency of relapse and recurrence of symptoms can be influence by poor compliance with medications. Although most of the care givers reported one problem or the other in relation to medication adherence (mainly antipsychotics and mood stabilizers), these problems were not objectively measured.

It has been documented that early onset bipolar disorder in the childhood and adolescent period might be characterized by more severe disease course in terms of symptoms chronicity and presence of co-morbid disorders which largely would influence long term functioning and quality of life in the affected children and adolescents. ${ }^{12}$ This dictates the need to set a priority for evaluating outcome in early onset bipolar disorder in children and adolescents in this environment where data on the subject are limited.

The finding in this study that presence of co-morbid disorders had a negative effect on functioning in bipolar disorder has been noted by previous studies carried out 
mostly in developed countries of the world. 5,13,14,15 The negative impact of co-morbid psychoactive substance use disorders was particularly emphasized. 5,13,16,17,18 There have been suggestions that impaired functioning in patients with bipolar disorder may be a predictive factor for relapse and fluctuation of mood symptom. ${ }^{19}$ Therefore, a bidirectional approach to the relationship between functioning and mood symptoms in bipolar disorder has been proposed. ${ }^{19}$ In planning interventions for these children and adolescents, attention needs to be focused on promoting and encouraging factors that predict good functioning such as married parental status, moderate involvement in religious activity, and dealing with the problem of co-morbid disorders, especially comorbid psychoactive substance use among others. ${ }^{11}$

\section{Limitations}

The presence of co-morbid disorders was mentioned in this study, however the details of the specific co-morbid disorders had been detailed elsewhere in another publication. ${ }^{11}$ That study assessed the association between co-morbid disorders and history of sexual risk behaviour among the adolescents. ${ }^{11}$ Most of the information gathered on co-morbidity in the said study ${ }^{11}$ was based on unstructured clinical interviews of the adolescents and their parents rather than using standardized algorithms. However, this was not expected to influence significantly the findings of the study because the interviews were conducted by trained specialists in psychiatry.11

Robustness of the findings of the present study might be limited by the fact that the study was a one year assessment and follow up. Longer longitudinal follow up studies assessing long-term functioning and its correlates among these children and adolescents with bipolar disorder would have provided more robust findings on which a more conclusive inference could be drawn. However, such future long-term longitudinal follow up studies in this environment could build on the template of the present findings.

Another limitation of the findings of this study was our inability to assess objectively the compliance or adherence to medications in the adolescents studied. This could have had an influence on recurrence of symptoms, and by extension, affected their functioning.

\section{Conclusion}

Impaired level of functioning complicates bipolar disorder in these adolescents. Functioning in the adolescents is influenced by a number of factors that need to be considered when planning interventions for child and adolescent bipolar disorder in this environment. Future long-term follow up studies are desirable that would longitudinally investigate outcome and its correlates in children and adolescents with bipolar disorder in this environment.

\section{Acknowledgements}

We thank all the adolescents and their care givers that consented to participate in the study.

\section{References}

1. Sadock BJ, Sadock VA. Kaplan \& Sadock's Concise Textbook of Child and Adolescent Psychiatry; Wolters Kluwer/Lippincott Williams \& Wilkins; Chapter 14: $132-133$.

2. Geller B, Bolhofuer $K$, Craney JL, Williams M, DelBello MP,
Gundersen K. Psychosocial functioning in a pre-pubertal and early adolescent bipolar disorder phenotype. J Am Acad Child Adolesc Psychiatry 2000; 39(12): 1543 - 1548.

3. Birmaher B, Axelson D, Strober M, Gill MK, Valeri S, Chiappetta L, et al. Clinical course of children and adolescents with bipolar spectrum disorders. Arch Gen Psychiatry 2006; 63(2): 175 - 183.

4. Birmaher B, Axelson D. Course and outcome of bipolar spectrum disorder in children and adolescents: a review of the existing literature. Dev Psychopathol. 2006; 18(4): 1023 - 1035.

5. Krishman KR. Psychiatric and medical co-morbidities of bipolar disorder. Psychosom Med 2005; 67(1): 1 - 8.

6. Gureje O, Omigbodun OO, Gater R, Acha RA, Ikuesan BA, Morris J. Psychiatric disorders in a paediatric primary care clinic. $\mathrm{Br} \mathrm{J}$ Psychiatry 1994; 165(4): 527 - 530.

7. Omigbodun O, Gureje O, Gater R, Ikuesan B, Adebayo E. Psychiatric morbidity in a Nigerian paediatric primary care service: a comparison of two screening instruments. Soc Psychiatry Psychiatr Epidemiol 1996: 31(3-4): 186 - 193.

8. Bakare MO, Omigbodun OO, Kuteyi OB, Meremikwu MM, Agomoh AO. Psychological complications of childhood chronic physical illness in Nigerian children and their mothers: the implication for developing pediatric liaison services. Child Adoles Psychiatry Ment Health 2008; 2 (1): 34.

9. Diagnostic and Statistical Manual of Mental Disorders, 4th Edition (DSM-IV). American Psychiatric Association, 1994.

10. Schaffer D, Gould MS, Brasic J, Ambrosini P, Fisher P, Bird H, et al. A children's global assessment scale (C-GAS). Arch Gen Psychiatry 1983; 40(11): 1228 - 1231.

11. Bakare MO, Agomoh AO, Ebigbo PO, Onyeama GM, Eaton J, Onwukwe JU, et al. Co-morbid disorders and sexual risk behavior in Nigerian adolescents with bipolar disorder. Int Arch Med 2009; 2(1): 16.

12. Perlis RH, Miyahara S, Marangell LB, Wisniewski SR, Ostacher M, DelBello MP, et al. Long-term implications of early onset in bipolar disorder: data from the 1000 participants in the systematic treatment enhancement program for bipolar disorder (STEP-BD). Biol Psychiatry 2004; 55(9): 875 - 881.

13. Goldstein TR, Birmaher B, Axelson D, Ryan ND, Strober MA, Gill MK, et al. History of suicide attempts in pediatric bipolar disorder: factors associated with increased risk. Bipolar Disord 2005; 7(6): 525 $-535$.

14. Romero S, Birmaher B, Axelson D, Goldstein T, Goldstein BI, Gill MK, et al. Prevalence and correlates of physical and sexual abuse in children and adolescents with bipolar disorder. J Affect Disord 2009; $112(1-3): 144-150$.

15. Baldassano CF. Illness course, co-morbidity, gender and suicidality in patients with bipolar disorder. J Clin Psychiatry 2006; 67 Suppl II: $8-11$.

16. Goldstein BI, Strober MA, Birmaher B, Axelson DA, EspositoSmythers C, Goldstein TR, et al. Substance use disorders among adolescents with bipolar spectrum disorders. Bipolar Disord 2008; 10(4): $469-478$.

17. Cardoso BM, Kauer Sant' Anna M, Dias VV, Andreazza AC, Cereser KM, Kapczinski F. The impact of co-morbid alcohol use disorder in bipolar patients. Alcohol 2008; 42(6): 451 -457.

18. Baethge C, Baldessarini RJ, Khalsa HM, Hennen J, Salvatore P, Tohen M. Substance abuse in first episode bipolar I disorder: indications for early intervention. Am J Psychiatry 2005; 162 (5): 1008 - 1010.

19. Weinstock LM, Miller IW. Functional impairment as a predictor of short-term symptom course in bipolar I disorder. Bipolar Disord 2008; 10(3): $437-442$. 